Check for updates

Cite this: J. Mater. Chem. A, 2020, 8 , 19788

Received 20th April 2020 Accepted 29th July 2020

DOI: $10.1039 / d 0 t a 04223 d$

rsc.li/materials-a

\section{Active faceted nanoporous ruthenium for electrocatalytic hydrogen evolution $\uparrow$}

\author{
Abdillah Sani Bin Mohd Najib, (iD abc Muhammad lqbal, (D) b \\ Mohamed Barakat Zakaria, (D) d Shusaku Shoji, ${ }^{e}$ Yohei Cho, ${ }^{e}$ Xiaobo Peng, (D) b \\ Shigenori Ueda, (D) fg Ayako Hashimoto, (D) Takeshi Fujita, (D) h Masahiro Miyauchi, (D) e \\ Yusuke Yamauchi (D)*di and Hideki Abe (D)*ab
}

\begin{abstract}
Nanoporous ruthenium ( $\mathrm{np}-\mathrm{Ru}$ ) comprising reaction active facets is synthesized from a ruthenium-cerium $\left(\mathrm{Ru}_{2} \mathrm{Ce}\right)$ alloy precursor. Spontaneous nanophase separation of $\mathrm{Ru}_{2} \mathrm{Ce}$ in an oxidative atmosphere results in a lamellar nanocomposite consisting of Ru metal and cerium oxide $\left(\mathrm{CeO}_{2}\right)$. Selective leaching of the $\mathrm{Ru}-\mathrm{CeO}_{2}$ nanocomposite in sulfuric acid yields $\mathrm{np}-\mathrm{Ru}$ with a high surface area of 48 $\mathrm{m}^{2} \mathrm{~g}^{-1}$, predominantly surrounded by reaction active $\{10 \overline{1} 0\}$ facets. Active-faceted $\mathrm{np}-\mathrm{Ru}$ efficiently catalyzed the hydrogen evolution reaction (HER) in acidic media at an overpotential of $+74 \mathrm{mV} v$ s. the reversible hydrogen electrode, which is $20 \mathrm{mV}$ lower than that for carbon-supported $\mathrm{Ru}(\mathrm{Ru} / \mathrm{C})$ and rather close to $+58 \mathrm{mV}$ for state-ofthe-art $\mathrm{Pt} / \mathrm{C}$. Np-Ru has great potential in broad applications such as hydrogen battery electrodes because of its low HER overpotential and scalable synthetic protocol.
\end{abstract}

Nanoporous materials are one of the confocal subjects of broad research on catalysts, absorbates and sensors due to their large

${ }^{a}$ Graduate School of Science and Technology, Saitama University, Shimo-Okubo 255, Saitama 338-8570, Japan. E-mail: BE.Hideki@Anims.go.jp

${ }^{b}$ National Institute for Materials Science, 1-1 Namiki, Tsukuba, Ibaraki 305-0044, Japan

${ }^{c}$ School of Mechanical engineering, Faculty of engineering, Universiti Teknologi Malaysia, Skudai, Johor Bahru, 81310, Malaysia

${ }^{d}$ Australian Institute for Bioengineering and Nanotechnology (AIBN) and School of Chemical Engineering, The University of Queensland, Brisbane, QLD, 4072, Australia.E-mail: y.yamauchi@uq.edu.au

${ }^{e}$ Department of Materials Science and Engineering, School of Materials and Chemical Technology, Tokyo Institute of Technology, Ookayama 2-12-1, Meguro-ku, Tokyo 1528552, Japan

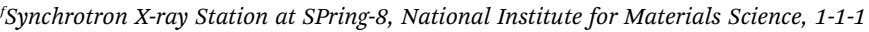
Kouto, Sayo, Hyogo, 679-5148, Japan

${ }^{g}$ National Institute for Materials Science, 1-2-1 Sengen, Tsukuba, Ibaraki, 305-0047, Japan

${ }^{h}$ School of Environmental Science and Engineering, Kochi University of Technology, 185 Miyanokuchi, Tosayamada, Kami City, Kochi 782-8502, Japan

${ }^{i}$ Department of Plant \& Environmental New Resources, Kyung Hee University, 1732 Deogyeong-daero, Giheung-gu, Yongin-si, Gyeonggi-do 446-701, South Korea

$\dagger$ Electronic supplementary information (ESI) available. See DOI: $10.1039 /$ dota04223d surface area as a stage for different molecular events. ${ }^{1,2}$ Metallic nanoporous materials, i.e., nanoporous metals, are of particular and growing interest because of their high thermal/electric conductivity, magnetic, and plasmonic properties..$^{3-5}$ There are a number of successful attempts to tailor the nanopores in size, dispersity and connectivity, using templates such as block copolymers, liquid crystals and/or mesoporous silica. ${ }^{6-11}$ The nanoporous metals synthesized in such bottom-up approaches are inherently an aggregate of individual clusters deposited to the template surface. Different approaches such as dealloying of prepared alloy precursors may yield more favorable nanoporous metals for electrocatalytic applications because of their continuously connected network structure. ${ }^{12-17}$ The so far developed dealloying methods can, however, hardly tailor the surface atomic arrangement of nanoporous metals: dealloyed metals are usually surrounded by randomly developed facets, some of which can inhibit targeted surface reactions. ${ }^{18}$

Herein, we propose another versatile method to synthesize facet-tailored nanoporous metals, utilizing a spontaneous nanophase-separation phenomenon of alloy precursors. An alloy precursor consisting of the target metal and an oxyphilic metal counterpart is subjected to an oxidative atmosphere to promote internal oxygen diffusion. Selective oxidation of the counterpart metal results in a spatially ordered metal-oxide nanocomposite. As the result of a strong metal-oxygen interaction at the epitaxial interface, the metal phase is allowed to develop energetically unfavorable crystal planes. The oxide counterpart is finally leached out in solvent to yield the targeted nanoporous metal that is surrounded by reaction active facets.

Precious-Group Metals (PGMs) especially platinum (Pt) serve as prominent catalysts for different chemical reactions. ${ }^{19-22}$ Electrolytic hydrogen $\left(\mathrm{H}_{2}\right)$ evolution from aqueous solution (Hydrogen Evolution Reaction: HER) can potentially produce $\mathrm{CO}_{2}$-free $\mathrm{H}_{2}$, yet is precluded from broad use due to the lack of reaction active and economically sound electrocatalysts. ${ }^{23}$ It is highly desirable to materialize nanoporous ruthenium (np-Ru) as an efficient alternative to the state-of-the-art, expensive Pt electrocatalysts for the HER (Pt: $30 \$ \mathrm{~g} \mathrm{~g}^{-1}$; Ru: $8 \$ \mathrm{~g}^{-1}$ - Johnson 
Matthey). However, to date, most of the attempts to synthesize $\mathrm{np}-\mathrm{Ru}$ by conventional dealloying ${ }^{\mathbf{2 4 , 2 5}}$ and organometallic decomposition ${ }^{\mathbf{2 6}}$ methods resulted in the emergence of random facets which diminished the catalytic performance: the $\{10 \overline{1} 0\}$ facets of hexagonal $\mathrm{Ru}$ are theoretically demonstrated as most HER active, but less readily developed than any of the other energetically favorable facets. ${ }^{27}$

To demonstrate the priority of the proposed approach for nanoporous metals, we have successfully synthesized np-Ru from an precursor alloy consisting of $\mathrm{Ru}$ and a highly oxyphilic metal counterpart, cerium (Ce) (Fig. 1). ${ }^{28} \mathrm{~A} \mathrm{Ru}_{2} \mathrm{Ce}$ alloy was first subjected to an oxidative environment to promote nanophase separation into a $\mathrm{Ru}-\mathrm{CeO}_{2}$ nanocomposite. The $\mathrm{Ru}$ and $\mathrm{CeO}_{2}$ phases were ordered in a nanometer-thick $(\sim 5 \mathrm{~nm})$ lamellar structure because oxygen atoms diffuse throughout the precursor so as to extend an epitaxial interface of the $\mathrm{CeO}_{2}\{110\}$ and $\mathrm{Ru}$ $\{10 \overline{1} 0\}$ planes. Selective leaching of the $\mathrm{CeO}_{2}$ phase in sulfuric acid $\left(\mathrm{H}_{2} \mathrm{SO}_{4}\right)$ finally yielded phase-pure, highly crystalline np-Ru that was predominantly surrounded by $\{10 \overline{1} 0\}$ facets. The active faceted $n p-R u$ efficiently promoted the HER in acidic media at a lower overpotential than carbon-supported $\mathrm{Ru}(\mathrm{Ru} / \mathrm{C})$ with a higher turn-over frequency (TOF) at $+100 \mathrm{mV} v s$. the reversible hydrogen electrode (RHE) compared to previously reported metallic np-Ru (Fig. S1 and S2 $\dagger$ ). ${ }^{26}$

The $\mathrm{Ru}_{2} \mathrm{Ce}$ alloy precursor was prepared by melting $\mathrm{Ru}$ and Ce metal ingots using an arc torch in a pure Ar atmosphere. The precursor alloy was then powdered with a mortar, sieved to 50$60 \mu \mathrm{m}$ in size and heated in a mixture of carbon monoxide (CO), oxygen and argon gas $\left(\mathrm{CO}: \mathrm{O}_{2}: \mathrm{Ar}=1: 1: 98\right.$ in volumetric ratio; flow rate $=60 \mathrm{~cm}^{3} \mathrm{~s}^{-1}$ ) at $600{ }^{\circ} \mathrm{C}$ for 12 hours. Powder $\mathrm{X}$ ray diffractometry (pXRD) demonstrated that the reflections from the $\mathrm{Ru}_{2}$ Ce precursor were fully substituted by those from $\mathrm{Ru}$ metal and $\mathrm{CeO}_{2}$ after the atmosphere treatment (Fig. S3 $\dagger$ ). Cross-sectional scanning transmission electron microscopy (STEM) observation further showed that the atmosphere-treated $\mathrm{Ru}_{2} \mathrm{Ce}$ alloy was converted into a $\mathrm{Ru}-\mathrm{CeO}_{2}$ nanocomposite consisting of a highly ordered lamellar structure with a spatial period of $5 \mathrm{~nm}$ (Fig. 2a, b; see Fig. S4†). The bright and dark contrasted areas in Fig. 2a correspond to the metal $\mathrm{Ru}$ and $\mathrm{CeO}_{2}$ phases, respectively, as supported by compositional mapping (Fig. 2b; see Fig. S5† for details).

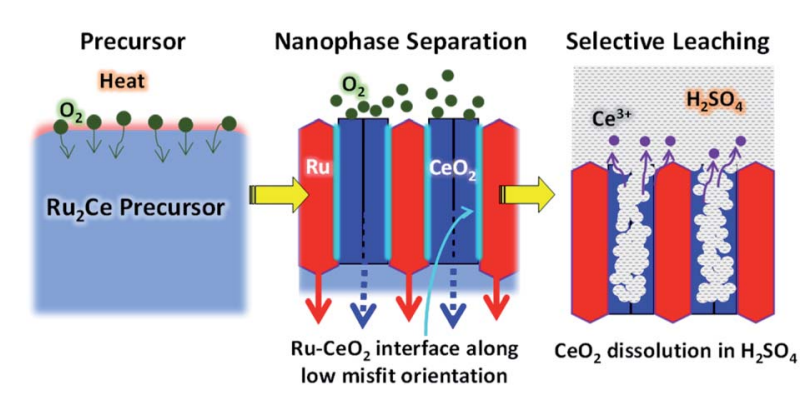

Fig. 1 Synthetic protocol for active faceted $n p-R u$. Heating the $\mathrm{Ru}_{2} \mathrm{Ce}$ alloy precursor in an oxidative atmosphere results in a nanophaseseparated metal-oxide composite having an extended Ru\{1010\}/ $\mathrm{CeO}_{2}\{110\}$ epitaxial interface. The nanocomposite is finally leached in sulfuric acid to selectively dissolve $\mathrm{CeO}_{2}$, yielding active faceted $\mathrm{np}$ Ru.

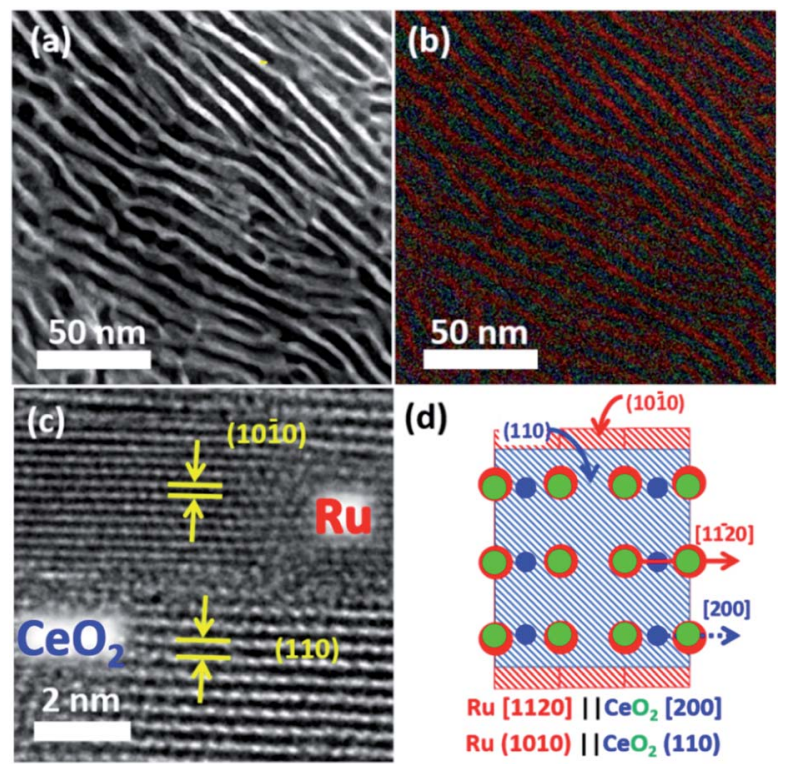

Fig. 2 (a) Cross-sectional annular-dark field (ADF) scanning transmission electron microscopy (STEM) image and (b) compositional mapping image of a nanophase-separated $\mathrm{Ru}-\mathrm{CeO}_{2}$ composite obtained from precursor $\mathrm{Ru}_{2} \mathrm{Ce}$ via atmosphere treatment. The red and dark green stripes correspond to the $\mathrm{Ru}$ and $\mathrm{CeO}_{2}$ phases, respectively. (c) High-resolution transmission electron microscopy (TEM) image of the $\mathrm{Ru}-\mathrm{CeO}_{2}$ interface. (d) A schematic model for the epitaxial relationship between the $\mathrm{Ru}\{1010\}$ and $\mathrm{CeO}_{2}\{110\}$ planes. The red, blue and green circles correspond to the $\mathrm{Ru}, \mathrm{Ce}$ and $\mathrm{O}$ atoms, respectively.

The $\mathrm{Ru}$ phase was developed such that the $\mathrm{Ru}\{10 \overline{1} 0\}$ and $\mathrm{CeO}_{2}\{110\}$ planes were oriented with an epitaxial relationship (Fig. 2c; S3 and S7 $\dagger$ ). The interatomic distance of oxygen on the $\mathrm{CeO}_{2}$ (110) planes along the [100] axis, $2.7 \AA$, matches with the interatomic distance of $\mathrm{Ru}$ on the $\mathrm{Ru}(10 \overline{1} 0)$ planes along the [11200] axis, $2.7 \AA$ (Fig. S8 $\dagger$ ). ${ }^{29}$ This lattice matching may minimize the interfacial energy between the metal and oxide phases to favor the epitaxial $\mathrm{Ru}\{10 \overline{1} 0\} / \mathrm{CeO}_{2}\{110\}$ interface. Note that in the pXRD spectra, the $\{10 \overline{1} 0\}$ reflections were clearly visible for $\mathrm{np}-\mathrm{Ru}$ due to the preferred growth of the $\{10 \overline{1} 0\}$ facets, while much weak reflections were recognized for directly dealloyed $\mathrm{Ru}_{2} \mathrm{Ce}$ having polycrystalline nature (Fig. S3†).

Subsequent selective leaching of $\mathrm{CeO}_{2}$ from the $\mathrm{Ru}-\mathrm{CeO}_{2}$ nanocomposite (Fig. 3a) in $\mathrm{H}_{2} \mathrm{SO}_{4}$ solution resulted in the targeted, faceted np-Ru (Fig. 3b). The $\mathrm{CeO}_{2}$ phase was completely removed as evidenced by pXRD and hard X-ray photoemission spectroscopy (HAXPES) (Fig. S3 and S9†). The Ru\{1010\} facets, which were extended via the formation of the $\mathrm{Ru}\{1010\} / \mathrm{Ce}\{110\}$ interface in the nanophase separation of the precursor alloy, became fully exposed to the environment after the elimination of the $\mathrm{CeO}_{2}$ matrix (Fig. $3 \mathrm{c}$ and d, see Fig. S10 $†$ for FFT analysis). The specific surface area of np-Ru was quantified by BET (BrunauerEmmett-Teller) surface area measurements as $48 \mathrm{~m}^{2} \mathrm{~g}^{-1}$. The nitrogen $\left(\mathrm{N}_{2}\right)$ adsorption-desorption isotherm demonstrated a hysteresis trend, showing that np-Ru consisted of slit-shaped and/or lamellar pores, as expected from the transmission electron microscopy (TEM) observations (Fig. S11†). 

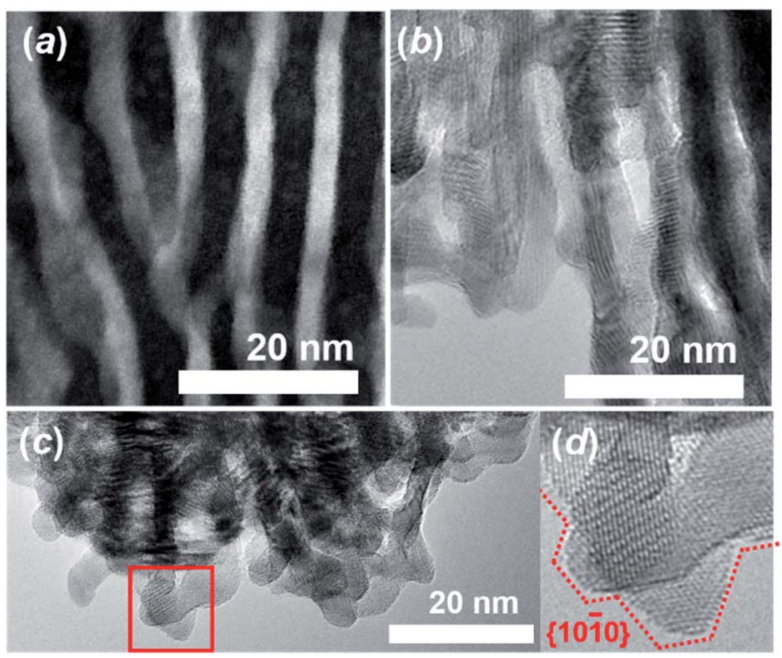

Fig. 3 (a) Cross-sectional ADF STEM image of a nanophase-separated $\mathrm{Ru}-\mathrm{CeO}_{2}$ nanocomposite (bright: $\mathrm{Ru}$; dark: $\mathrm{CeO}_{2}$ ) and (b) a brightfield transmission electron microscopy (TEM) image of active faceted $\mathrm{np}-\mathrm{Ru}$ obtained via a selective leaching of the $\mathrm{Ru}-\mathrm{CeO}_{2}$ nanocomposite (dark: Ru; bright: vacuum). (c) Bright-field TEM images of active faceted $\mathrm{np}-\mathrm{Ru}$. The atomic fringes in (d) correspond to the Ru $\{1010\}$ planes.

Cyclic Voltammetry (CV) was conducted in $0.5 \mathrm{M} \mathrm{H}_{2} \mathrm{SO}_{4}$ solution using a rotating glassy-carbon disk electrode to identify the preferential facets of np-Ru. Fig. 4a presents the $\mathrm{CV}$ profiles for $\mathrm{np}-\mathrm{Ru}$ and carbon-supported $\mathrm{Ru}(\mathrm{Ru} / \mathrm{C}$; loading weight: $5 \%)$. $\mathrm{Ru} / \mathrm{C}$ showed a typical CV profile for polycrystalline Ru with no preferential facets. By contrast, np-Ru showed a CV profile having distinct peaks at $+0.30 \mathrm{~V}$ and $+0.52 \mathrm{~V}$ vs. RHE, corresponding to the electrochemical oxidation of chemisorbed
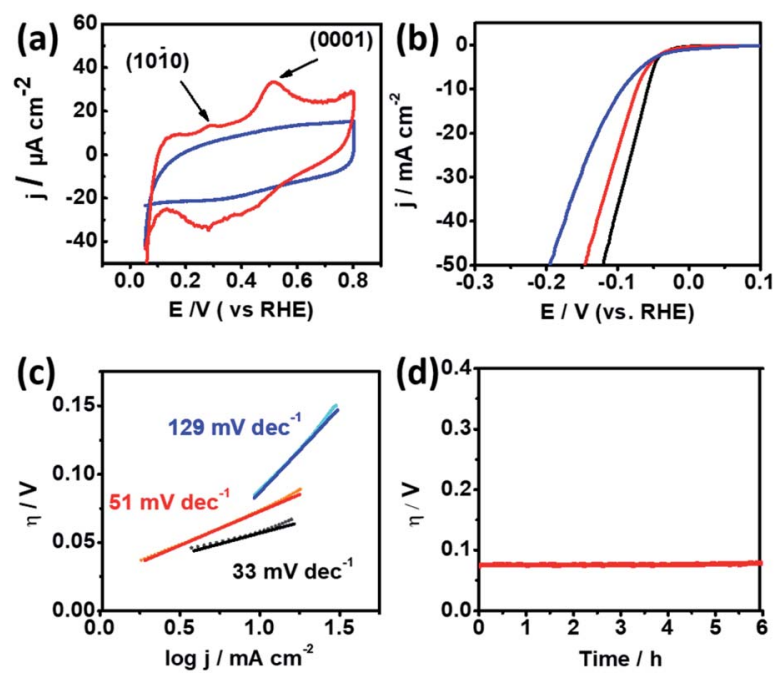

Fig. 4 (a) Cyclic Voltammetry (CV) profiles for $\mathrm{np}-\mathrm{Ru}$ (red) and Ru/C (blue), and (b) Linear Sweep Voltammetry (LSV) profiles and the corresponding (c) Tafel plots for $n p-R u$ (red), Ru/C (blue) and Pt black (black). The corresponding Tafel slopes are shown in the inset. (d) Chronogalvanometry profile for $\mathrm{np}-\mathrm{Ru}$ (red) acquired at a HER current density of $10 \mathrm{mV} \mathrm{s}^{-1}$. All the experiments were conducted in $0.5 \mathrm{M}$ $\mathrm{H}_{2} \mathrm{SO}_{4}$ solution using platinum wire as the counter electrode. hydrogen atoms over the $\{10 \overline{1} 0\}$ and $\{0001\}$ facets, respectively. ${ }^{30}$ As expected from the TEM characterization (Fig. $2 \mathrm{~d}-\mathrm{f}$ and $\mathrm{S} 7 \dagger)$, np-Ru was predominantly surrounded by the $\{10 \overline{1} 0\}$ and $\{0001\}$ facets.

Linear Sweep Voltammetry (LSV) was performed in $0.5 \mathrm{M}$ $\mathrm{H}_{2} \mathrm{SO}_{4}$ in a potential range from $+100 \mathrm{mV}$ to $-400 \mathrm{mV} v$ s. RHE to evaluate the HER performance of the faceted np-Ru catalyst (by considering overpotential at current density, $j$ of $10 \mathrm{~mA}$ $\left.\mathrm{cm}^{-2}\right) \cdot{ }^{26,31,32}$ As a comparison, $\mathrm{Ru} / \mathrm{C}$ and Pt black were also tested under the same conditions. The polarization curves resulting from LSV demonstrated that np-Ru had an overpotential of $-74 \mathrm{mV}$. This value was significantly low compared to the overpotential of $-94 \mathrm{mV}$ for $\mathrm{Ru} / \mathrm{C}$, and rather close to that for the state-of-the-art Pt/C, $-58 \mathrm{mV}$ (Fig. 4b).

We performed LSV using a graphite rod as the counter electrode to avoid possible contamination by redeposition of $\mathrm{Pt}$ (Fig. S12 $\dagger$ ). ${ }^{33}$ Another control LSV experiment was conducted in a perchloric acid $\left(\mathrm{HClO}_{4}\right)$ electrolyte to avoid possible contamination by adsorption of sulfuric anions $\left(\mathrm{SO}_{4}{ }^{2-}\right.$ ) (Fig. S13†). The $\mathrm{np}-\mathrm{Ru}$ catalyst was superior to $\mathrm{Ru} / \mathrm{C}$ in the both cases in terms of higher onset potentials. np-Ru also showed higher HER mass activity than a non-supported metal Ru catalyst (Fig. S14, see the $\mathrm{ESI} \dagger$ for the synthetic details of metal Ru). The electrochemical surface areas (ECSAs) for $\mathrm{np}-\mathrm{Ru}$ and $\mathrm{Ru} / \mathrm{C}$ were determined to be 39.60 and $73.87 \mathrm{~m}^{2} \mathrm{~g}^{-1}$, respectively, by measuring the doublelayer capacitance in the electrolyte solution (Fig. S15, see the ESI $\dagger$ for experimental details). ${ }^{34-38}$ The current density normalized to the ECSA finally supported that np-Ru was superior to $\mathrm{Ru} / \mathrm{C}$ in HER activity (Fig. S16†).

Furthermore, the Tafel slopes derived from LSV for $\mathrm{np}-\mathrm{Ru}$, $+51 \mathrm{mV} \mathrm{dec}{ }^{-1}$, was much lower than that for $\mathrm{Ru} / \mathrm{C},+129 \mathrm{mV}$ $\mathrm{dec}^{-1}$, and again closer to that of Pt black, $+33 \mathrm{mV} \mathrm{dec}^{-1}$. The np-Ru catalyst promoted the HER not only at a lower overpotential but also kinetically fast compared to Ru/C (Fig. 4c). In addition, the exchange current density at zero overpotential $\left(J_{0}\right)$ from the Tafel extrapolation method for $\mathrm{np}-\mathrm{Ru}, \mathrm{PtB}$, and $\mathrm{Ru} / \mathrm{C}$ was estimated to be $22.67 \mathrm{~mA} \mathrm{~cm}{ }^{-2}, 17.25 \mathrm{~mA} \mathrm{~cm} \mathrm{~cm}^{-2}$, and $6.638 \mathrm{~mA} \mathrm{~cm}{ }^{-2}$, respectively (Fig. S17†). The np-Ru catalyst exhibited a higher exchange current density than $\mathrm{Ru} / \mathrm{C}$, indicating that the np-Ru surface had a so low energy barrier that charge is readily transported between the electrolyte and the catalyst surface.

It is acknowledged that there are three rate-determining steps associated with the HER in acidic media, resulting in different Tafel slopes: reduction of hydronium ions, $\mathrm{H}_{3} \mathrm{O}^{+}$to $\mathrm{H}$ adatoms, $\mathrm{H}_{\text {ads }}$ (Volmer reaction: $\mathrm{H}_{3} \mathrm{O}^{+}+\mathrm{e}^{-}+\mathrm{M} \rightarrow \mathrm{H}_{\text {ads }}+\mathrm{H}_{2} \mathrm{O}$; $A$ $=120 \mathrm{mV} \mathrm{dec}^{-1}$ ), electrochemical desorption (Heyrovsky reaction: $\mathrm{H}_{\mathrm{ads}}+\mathrm{H}_{3} \mathrm{O}^{+}+\mathrm{e}^{-} \rightarrow \mathrm{H}_{2}+\mathrm{H}_{2} \mathrm{O}+\mathrm{M} ; A=40 \mathrm{mV} \mathrm{dec}{ }^{-1}$ ) and pairing of $\mathrm{H}_{\text {ads }}$ to form molecular $\mathrm{H}_{2}$ (Tafel reaction: $2 \mathrm{H}_{\text {ads }} \rightarrow$ $\mathrm{H}_{2}+2 \mathrm{M} ; A=30 \mathrm{mV} \mathrm{dec}{ }^{-1}$ ) where $\mathrm{M}$ corresponds to the surface empty site. ${ }^{39,40}$

Based on the calculated Tafel slopes, the rate-determining step for $\mathrm{Ru} / \mathrm{C}$ is assigned to the Volmer reaction in which $\mathrm{H}_{3} \mathrm{O}^{+}$reduction to $\mathrm{H}_{\text {ads }}$ was relatively slow. By contrast, the np$\mathrm{Ru}$ catalyst promotes the HER predominantly via the VolmerHeyrovsky reaction, where $\mathrm{H}_{\text {ads }}$ was readily available to be desorbed via electrochemical pathways. As theoretically 
demonstrated by $\mathrm{Li}$ et al., the $\mathrm{Ru}\{10 \overline{1} 0\}$ and $\{0001\}$ facets moderately adsorb $\mathrm{H}_{\text {ads }}$ compared to the other facets including $\{11 \overline{2} 0\} .{ }^{27}$ The moderately adsorbed $\mathrm{H}_{\mathrm{ads}}$ onto the $\{10 \overline{1} 0\}$ facets can serve as an active intermediate for the other reactions, i.e., hydronium ions to molecular $\mathrm{H}_{2}$ (Heyrovsky) as for np-Ru, whereas too strongly adsorbed $\mathrm{H}_{\mathrm{ads}}$ depletes the surface empty site, $M$, slowing down further generation of active $\mathrm{H}_{\mathrm{ads}}$ (Volmer) as for Ru/C. ${ }^{41}$ Electrochemical impedance spectroscopy demonstrated a small arc diameter for $\mathrm{np}-\mathrm{Ru}$ compared to that for $\mathrm{Ru} / \mathrm{C}$, showing that $\mathrm{np}-\mathrm{Ru}$ had a lower resistance at the electrode/electrolyte interface (Fig. S18†). The low electrode/ electrolyte resistance is associated with better diffusion of hydrogen, electrolyte, and intermediate species. ${ }^{34}$ The improved HER catalytic activity of np-Ru is thus partly attributed to the lowered charge-transfer resistance at the catalyst/electrode interface.

The catalyst stability of np-Ru was evaluated by chronogalvanometry in $0.5 \mathrm{M} \mathrm{H}_{2} \mathrm{SO}_{4}$ solution at $+10 \mathrm{~mA}$ (Fig. $4 \mathrm{~d}$ ). The active faceted np-Ru exhibited a stable overpotential over 6 hours, supporting the reaction stability of the developed $\mathrm{Ru}$ $\{10 \overline{1} 0\}$ facets (see also Fig. S19† for chronoamperometric tests). TEM characterization has also confirmed that the np-Ru catalyst after the stability test retained not only the nanoporous structure but also the catalytically active $\{10 \overline{1} 0\}$ facets (Fig. S20 and $\mathrm{S} 21 \dagger$ ).

\section{Conclusions}

A nanoporous ruthenium (np-Ru) catalyst surrounded by reaction-active $\{10 \overline{1} 0\}$ facets has been successfully materialized via leaching of a lamellar $\mathrm{Ru}-\mathrm{CeO}_{2}$ nanocomposite that spontaneously emerges from a $\mathrm{Ru}_{2} \mathrm{Ce}$ precursor alloy in an oxidative atmosphere. $\mathrm{Np}-\mathrm{Ru}$ can be a rational alternative to Pt catalysts because of its low hydrogen evolution reaction (HER) overpotential, high $\mathrm{H}_{2}$ generation rate, long-term reaction stability, and low material cost. The active faceted $\mathrm{np}-\mathrm{Ru}$ can be further improved in catalytic performance through hybridization with promoter nanomaterials such as carbon nanotubes and/or graphene materials, contributing to future social implementation of $\mathrm{CO}_{2}$-free hydrogen resources. ${ }^{42,43}$ Finally, the proposed material design strategy for $\mathrm{np}-\mathrm{Ru}$, i.e., the utilization of nanophase separation of precursor alloys, will open up unexplored synthetic routes toward a wide variety of nanoporous metals.

\section{Conflicts of interest}

There are no conflicts to declare.

\section{Acknowledgements}

This work was preliminarily supported by the JST CREST program (grant no. JPMJCR15P1) and the JST PRESTO program towards "Innovative Catalysts" (grant no. JPMJPR17S7). This work was carried out by utilizing the facility of the NIMS TEM Station and was supported by the Global Research Center for Environment and Energy based on Nanomaterials Science. The
HAXPES measurements were performed with the approval of the NIMS Synchrotron X-ray Station (Proposal No. 2016A4607, 2016B4600, 2017A4602, 2017B4605, 2018A4600, 2018B4601, 2019A4600 and 2019B4601). This work was performed in part at the Queensland node of the Australian National Fabrication Facility (ANFF), a company established under the National Collaborative Research Infrastructure Strategy to provide nano and microfabrication facilities for Australia's researchers. This work was also partly funded by KAKENHI (JP16H02293).

\section{Notes and references}

1 S. Bhattacharyya, Y. Mastai, R. Narayan Panda, S.-H. Yeon and M. Z. Hu, J. Nanomater., 2014, 2014, 275796.

2 S. Ameen, M. S. Akhtar, R. Godbole and H.-S. Shin, An Introduction to Nanoporous Materials, IntechOpen, 2019.

3 R. Ron, E. Haleva and A. Salomon, Adv. Mater., 2018, 30, 1706755.

4 Y. Tang, B. Tang, Q. Li, J. Qing, L. Lu and K. Chen, Exp. Therm. Fluid Sci., 2013, 44, 194-198.

5 Q. Xu, H. Wang, X. Jiang and Y. Yamauchi, in Nanoporous Materials, CRC Press, 2013, pp. 183-200.

6 B. Jiang, C. Li, Ö. Dag, H. Abe, T. Takei, T. Imai, M. S. A. Hossain, M. T. Islam, K. Wood, J. Henzie and Y. Yamauchi, Nat. Commun., 2017, 8, 1-8.

7 B. R. Wiesenauer and D. L. Gin, Polym. J., 2012, 44, 461-468. 8 X. Zhang, W. Lu, J. Dai, L. Bourgeois, J. Yao, H. Wang, J. R. Friend, D. Zhao and D. R. MacFarlane, Sci. Rep., 2014, 4, 1-5.

9 H. Luo, L. Sun, Y. Lu and Y. Yan, Langmuir, 2004, 20, 1021810222.

10 J. H. Nam, Y. Y. Jang, Y. U. Kwon and J. Do Nam, Electrochem. Commun., 2004, 6, 737-741.

11 V. Malgras, Q. Ji, Y. Kamachi, T. Mori, F.-K. Shieh, K. C.-W. Wu, K. Ariga and Y. Yamauchi, Bull. Chem. Soc. Jpn., 2015, 88, 1171-1200.

12 L. Zhang, H. Chang, A. Hirata, H. Wu, Q. K. Xue and M. Chen, ACS Nano, 2013, 7, 4595-4600.

13 P. Haldar and A. Chatterjee, Acta Mater., 2017, 127, 379-388. 14 L. Zeng, C. You, X. Cai, C. Wang, X. Zhang and T. Liang, J. Mater. Res. Technol., 2020, 9, 6909-6915.

15 C. Qin, M. Zhang, B. Li, Y. Li and Z. Wang, Mater. Lett., 2020, 258, 126823.

16 Q. Lu, G. S. Hutchings, W. Yu, Y. Zhou, R. V. Forest, R. Tao, J. Rosen, B. T. Yonemoto, Z. Cao, H. Zheng, J. Q. Xiao, F. Jiao and J. G. Chen, Nat. Commun., 2015, 6, 1-8.

17 Y. T. Kim, P. P. Lopes, S. A. Park, A. Y. Lee, J. Lim, H. Lee, S. Back, Y. Jung, N. Danilovic, V. Stamenkovic, J. Erlebacher, J. Snyder and N. M. Markovic, Nat. Commun., 2017, 8, 1-8.

18 J. Erlebacher and I. McCue, Acta Mater., 2012, 60, 6164-6174. 19 S. Yang, Y. J. Tak, J. Kim, A. Soon and H. Lee, ACS Catal., 2017, 7, 1301-1307.

20 P. Xie, T. Pu, A. Nie, S. Hwang, S. C. Purdy, W. Yu, D. Su, J. T. Miller and C. Wang, ACS Catal., 2018, 8, 4044-4048.

21 X. Chen, X. Chen, S. Cai, J. Chen, W. Xu, H. Jia and J. Chen, Chem. Eng. J., 2018, 334, 768-779. 
22 G. Arteaga, L. M. Rivera-Gavidia, S. J. Martínez, R. Rizo, E. Pastor and G. García, Surfaces, 2019, 2, 16-31.

23 G. Zhao, K. Rui, S. X. Dou and W. Sun, Adv. Funct. Mater., 2018, 28, 1803291.

24 M. Hakamada, J. Motomura, F. Hirashima and M. Mabuchi, Mater. Trans., 2012, 53, 524-530.

25 Q. Zhou, H. Yang and C. Xu, Int. J. Hydrogen Energy, 2016, 41, 12714-12721.

26 S. Drouet, J. Creus, V. Collière, C. Amiens, J. García-Antón, X. Sala and K. Philippot, Chem. Commun., 2017, 53, 1171311716.

27 Y. Li, L. A. Zhang, Y. Qin, F. Chu, Y. Kong, Y. Tao, Y. Li, Y. Bu, D. Ding and M. Liu, ACS Catal., 2018, 8, 5714-5720.

28 A. S. B. M. Najib, X. Peng, A. Hashimoto, S. Shoji, T. Iida, Y. Bai and H. Abe, Chem.-Asian J., 2019, 14, 201900542.

29 S. Gates-Rector and T. Blanton, Powder Diffr., 2019, 34, 352360.

30 N. S. Marinkovic, M. B. Vukmirovic and R. R. Adzic, in Modern Aspects of Electrochemistry, Springer, New York, 2008, pp. 1-52.

31 M. G. Walter, E. L. Warren, J. R. McKone, S. W. Boettcher, Q. Mi, E. A. Santori and N. S. Lewis, Chem. Rev., 2010, 110, 6446-6473.

32 Y. Gorlin and T. F. Jaramillo, J. Am. Chem. Soc., 2010, 132, 13612-13614.

33 M. B. Zakaria, RSC Adv., 2016, 6, 10341-10351.
34 M. B. Zakaria, M. Hu, M. Pramanik, C. Li, J. Tang, A. Aldalbahi, S. M. Alshehri, V. Malgras and Y. Yamauchi, Chem.-Asian J., 2015, 10, 1541-1545.

35 A. A. Alireza, N. Hamnabard, S. M. H. Meshkati, M. Pakan and Y. H. Ahn, Dalton Trans., 2019, 48, 5429-5443.

36 Z. Zhou, L. Wei, Y. Wang, H. E. Karahan, Z. Chen, Y. Lei, X. Chen, S. Zhai, X. Liao and Y. Chen, J. Mater. Chem. A, 2017, 5, 20390-20397.

37 C. C. L. McCrory, S. Jung, I. M. Ferrer, S. M. Chatman, J. C. Peters and T. F. Jaramillo, J. Am. Chem. Soc., 2015, 137, 4347-4357.

38 B. Seo, D. S. Baek, Y. J. Sa and S. H. Joo, CrystEngComm, 2016, 18, 6083-6089.

39 L. X. Chen, Z. W. Chen, Y. Wang, C. C. Yang and Q. Jiang, ACS Catal., 2018, 8, 8107-8114.

40 A. Kahyarian, B. Brown and S. Nesic, J. Electrochem. Soc., 2017, 164, H365-H374.

41 T. Shinagawa, A. T. Garcia-Esparza and K. Takanabe, Sci. Rep., 2015, 5, 1-21.

42 Y. Zheng, Y. Jiao, Y. Zhu, L. H. Li, Y. Han, Y. Chen, M. Jaroniec and S. Z. Qiao, J. Am. Chem. Soc., 2016, 138, 16174-16181.

43 D. H. Kweon, M. S. Okyay, S.-J. Kim, J.-P. Jeon, H.-J. Noh, N. Park, J. Mahmood and J.-B. Baek, Nat. Commun., 2020, 11, 1278. 